\title{
EVMiUATION OF ASPHAIiT MIXES DISINTEGEUV3JION CONTAIHING XNDUSTRIMi WASTES USING THE CANTABRO T
}

badreldeen amousa

\begin{abstract}
The industrial wastes prouduct need big areas to storage and how it is become disposal problems. To reduce the susceptibilty of asphalt mixes to disintegration under the effects of high stress, the main methodology that can be used, is the addition of industrial waste materials to asphalt mixes in order to improve its resistance to disintegration (performance) using cantabro test. The objective of this study is to investigate the resistance to disintegration (using cantabro test) of asphahic concrete mixes containing some industrial wastes subjected to dynamic impactloading. Selecting two types of industrial waste material were used in this investigation, tliese are iron blast furnace slag (IBFS) and steel brash at varied percent. Five types of mixes were employed in this investigation: Traditional mixes, traditional mixes with IBFS by percent $25 \%$ and $50 \%$ as coarse aggregate, traditional mixes with $4 \%$ and $6 \%$ steel brash as filler using 60/70 penetration grade asphalt cement.

Marshall design method was used to optimise the asphalt content. Also, tlie loss of stability and cantabro test are performed.

The results indicate the benefits that can be obtained from using IBFS and steel brash as industrial wastes product in terms of resistance to disintegration, also, these wastes improved the engineering properties for asphalt concrate mixes without adversely effecting the stability and Marshall stiffness
\end{abstract}

